\title{
Micrometeorological and Sap Flow Measurement of Water Vapour Exchanges in Olive: Scaling Up from Canopy to Orchard
}

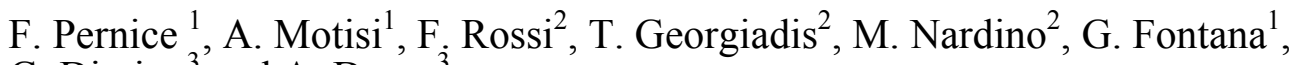

G. Dimino ${ }^{3}$ and A. Drago ${ }^{3}$

${ }^{1}$ Dipartimento di Colture Arboree, Palermo, Italy

${ }^{2}$ IBIMET-CNR, Istituto di Biometeorologia, Bologna, Italy

${ }^{3}$ Servizio Informativo Agrometeorologico Siciliano, Assessorato Agricoltura e Foreste, Palermo, Italy

Keywords: olive, sap flow, eddy covariance, tree transpiration, soil evaporation

\begin{abstract}
A comparison of water consumption evaluated at tree and orchard level was carried out in a commercial olive orchard located in Sicily using up-scaled sap-flow evapotranspiration estimations and eddy covariance measurements. Sap flow probes were installed on olive trees placed in one of the four plots characterizing a heterogeneous orchard. Trees were chosen, from a preliminary footprint analysis, in correspondence to the peak of the "relative normalized contribution" to flux for the prevailing wind conditions measured by an eddy covariance station localized in the central part of the orchard. Tree-age and planting density as well as main tree and orchard characteristics (Leaf Area per tree, within plot distribution of Trunk Cross Sectional Area TCSA, height and canopy diameter), were used to characterize the plot-to-plot differences. Both TCSA and LAI adopted as scaling parameters showed a high performance. A good agreement between ETec (daily integral of ECestimated evapotranspiration) and ETsf (up-scale sap flow ET estimate) was found in correspondence of limited canopy or soil evaporation conditions (absence of rain, dew, irrigation supply). Eddy covariance can be considered a reliable reference for up-scaled sap flow estimations of ET, and sap flow can be used as a replacement (proxy) of eddy covariance when atmospheric conditions invalidate the application of this technique to assess ET.
\end{abstract}

\section{INTRODUCTION}

Estimation of water consumption of olive orchards is an important aspect given the pervasive diffusion of this species in agricultural and non agricultural environments all over the Mediterranean basin. As an evergreen species, beside the agricultural implications related to irrigation management, olive water consumption can also have a large impact at the level of the hydrological cycles, particularly in environments such as the Mediterranean, where water scarcity is the most prominent issue of both natural and agricultural ecosystems for large part of the year.

Many methods have been used for the assessment of olive water consumption, from meteorological to micrometeorological and direct xylem flow estimates by sap flow sensors. In many cases, the need of an integration of these methods has arisen because of the many scaling issues imposed by specific peculiarities of olive trees. One major difficulty in scaling olive water consumption from tree to orchard level, for example, has been recognized (Fernandez et al., 2001; Giorio and Giorio, 2003) in the irregular shape of the trunk cross-sectional area, due to the presence of ribs and depressions along the trunk length, and in the occurrence of irregularities and large cavities within the trunk that make it difficult to single-out the conductive sapwood area within the xylem.

Independently on the method adopted, the determination of evapotranspiration at ecosystem level can be complicated by the heterogeneous distribution of vegetation elements, often having different functional properties (Williams et al., 2004). Sap flow measurements can help in partitioning total ET fluxes (tree transpiration and soil evaporation) when combined with eddy covariance estimates (Hutley et al., 2001), but scaling the results to the ecosystem may be complicated by the spatial and functional 
heterogeneity of vegetation (Schaeffer et al., 2000). Compared to forests, orchards are considered very homogeneous stands in terms of tree shape, age, spacing and row orientation. Inside the same orchard, however, differently-aged plots of trees may be present, as it occurs in the case of long-lived trees as olive. Also, a high degree of tree-totree variation, both in canopy size and root system expansion, can occur even in coetaneous stands, such as intensive orchards, because of between-tree competition. In these cases, it is needed to find an effective way to scale-up evapotranspiration data of each plot to eddy covariance data, referred to the entire orchard (Williams et al., 2004).

To study the scaling relationships that occur within an olive orchard composed by different plots, we have monitored water exchanges at tree and orchard level by sap-flow and eddy covariance measurements.

\section{MATERIAL AND METHODS}

Measurements were carried out starting on May 2006 in an olive orchard (cv. 'Nocellara del Belice') located in Western Sicily (Castelvetrano - Trapani). The orchard has an extension of about 11 ha and is formed by four different plots (A, B, C, D) (Fig. 1) characterized by different tree-age and planting density. Orchard and trees characteristics (height and canopy diameter averaged on 15 trees of each plot, leaf area per tree (LA) and leaf area index (LAI) (detected by a LAI-2000 - Plant Canopy Analyzer, LiCor Inc., Ne, USA)) are summarized in Table 1. All the plots were equipped with a drip-irrigation system with two 8-litres/hour emitters per tree. During the vegetative season, two irrigations were done for a total volume of $1500 \mathrm{~m}^{3} /$ ha. Soil texture is clay-loam, with $36,1 \%$ volumetric water content at field capacity and $17,4 \%$ at $-1.5 \mathrm{MPa}$ soil water potential. In accordance to the common cultural practices adopted in this traditional olivegrowing area, soil is clean-cultivated during the vegetative season whereas no weed control is done during the rainy season (autumn and winter). The two prevailing wind directions during the vegetative season are SE and NW. Air temperature, wind speed, relative humidity at $2 \mathrm{~m}$ and precipitation, measured by an automatic weather station installed nearby the orchard (500 m NE), were used to calculate ET0 by the FAO method. Soil temperature, using PT100 sensors, and volumetric water content (by Campbell SciCS616 TDR probes) were measured at different depths (from 5 to $60 \mathrm{~cm}$ below soil surface) and at different distances from the trees $(1 \mathrm{~m}$ from the tree up to $4 \mathrm{~m}$, mid point between rows). Soil temperature and moisture were used, together with meteorological data to estimate soil evaporation using the equation of Kondo et al. (1990).

\section{Eddy Covariance}

Wind velocity and temperature fluctuations were measured by a three dimensional sonic anemometer (CSAT3-3D, Campbell Sci, USA); water vapour concentration by an open-path, infrared absorption gas analyser (IRGA) LI7500 (LiCor Inc.). These instruments were installed at $8 \mathrm{~m}$ height from the ground (at about twice average tree height) on a mast located in a nearly central position of the orchard. On top of the same mast, a net radiometer (NR Lite, Campbell Sci., USA) was placed to measure the net available energy at the surface. Heat storage in the soil was measured through three soil heat flux plates (HFP01, Campbell Sci., USA) placed at a depth of $5 \mathrm{~cm}$ in three different points at the same distance from the girth of the mast. Wind, water vapour and temperature were sampled at $10 \mathrm{~Hz}$ and stored on a data logger (CR1000, Campbell Sci.). Eddy covariance post-processing was done to obtain 30-minute averages of fluxes.

\section{Sap Flow}

Measurements of water consumption at tree level were done in the plot A by using HPV (Heat Pulse Velocity) sap flow probes. To this purpose, two 4-cm sap flow probes with 4 thermocouples embedded (Tranzflo NZ Ltd, Palmerston North, NZ) were inserted in the trunks of three trees. The probes were positioned at North and South sides of the trunk at $50 \mathrm{~cm}$ from the ground and wired to a data-logger (CR10, Campbell Sci.) for heat-pulse control and measurement; sampling interval was $30 \mathrm{~min}$. Data of the two 
probes were processed according to Green et al. (2003) to integrate sap flow velocity over sapwood area and calculate transpiration. To this purpose, fraction of water in the sapwood was determined both on sample trees, during the experiment, and directly on the trees where sap flow probes were installed, at the end of the observation period. Woundeffect correction (Green et al., 2003) was done on a per-tree basis, comparing daily integrals of sap flow-derived tree transpiration against whole-tree gas exchange measurements performed in one-day-long sessions for each tree, by an open-system cuvette (Dragoni et al., 2005), selecting the set of coefficients that gave the least difference between the two measurement methods. Whole-tree gas-exchange measurement sessions were carried out in two different times of the year, three months apart, to check for long-term stability of calibration.

The trees for sap flow measurements were selected on the basis of their position relative to the flux tower mast, as in a preliminary EC footprint analysis (Schuepp et al., 1990). Their location within the orchard was chosen in correspondence to the maximum of the footprint function, calculated on the basis of the prevailing atmospheric conditions during the vegetative season. Calculations were limited to the diurnal hours, when maximum contribution to orchard latent heat flux is expected from tree transpiration. Plot A was preferred over Plot D (both aligned on the two prevailing wind directions) because of the lower within-plot soil variability. Within this area, three trees were selected to explore the full range of tree vigour, expressed as trunk cross-sectional area (TCSA). To estimate spatial variability of TCSA and leaf area per tree (LA) over the four plots, we used a distributed criterion, sampling uniformly over the orchard for a large number of trees per plot (40 trees, for each plot, for TCSA: about 5\% of the trees in each plot).

Regression equations between daily integrals of sap flow-estimated tree transpiration (Tsf) and TCSA or, alternatively, LA were calculated for each day and used for up-scaling sap flow data to plot A level. Plot A evapotranspiration $\left(\mathrm{ET}_{\mathrm{A}}\right)$ was calculated as the sum of up-scaled Tsf and soil evaporation (E) estimated by the Kondo model. Soil evaporation was almost negligible in the observation period, with a maximum of $0.3 \mathrm{~mm} /$ day.

Evapotranspiration of the other plots was calculated from $\mathrm{ET}_{\mathrm{A}}$, adjusting for differences in orchard LAI or total TCSA (basal area) relative to plot A. As an exception, due to tree-age ( $>150$ years), because of the irregular trunk shape and to the presence of large cavities in the trunk and the main scaffold branches, scaling in plot $\mathrm{C}$ was done only on the basis of LAI. Comparison of up-scaled sap flow estimates of ET (ETsf) to ECestimated evapotranspiration (ETec) was performed taking into consideration the prevailing wind direction in an interval of 30 minutes, to consider which specific plot was contributing to the flux data (Williams et al., 2004).

\section{RESULTS AND DISCUSSION}

Daily integrals of tree-transpiration measured by sap flow sensors Tsf and from open system gas-exchange showed a good agreement both in the first and in the second calibration sessions (Fig. 2) after proper choice of the sets of wound-effect calibration coefficients. No changes in the relationship between whole-tree gas-exchange and sap flow water consumption estimations were found during the second session, after about 100 days. For the two calibration sessions, the same corrections factors (Green et al., 2003) were used $(3.0 \mathrm{~mm}$ wound-width calibration set for tree A and $2.6 \mathrm{~mm}$ woundwidth for trees $\mathrm{B}$ and $\mathrm{C}$ ), suggesting that only limited changes occurred in xylem properties during the measurement period, as already noticed by Fernandez et al. (2001) and Giorio and Giorio (2003).

For up-scaling of Tsf data to plot level, two different phytometric parameters were compared: TCSA and LA. The relationships between Tsf and such scaling parameters, tested by a regression analysis, resulted linear for all the days in the observation period (Fig. 3). Parameters of these regression equations reflect day-to-day changes in atmospheric evaporative demand, soil water availability and tree hydraulic architecture and, for this reason, they were calculated daily. In the case of TCSA, each regression 
equation in the observation period resulted highly significant, with $\mathrm{R}^{2}=0.79$ in the worst case (Fig. 3). Similar results were obtained for the regression of Tsf on LA, so that upscaling to plot A level by using any of these two scaling parameters yielded similar results. Since the observed Gaussian frequency distribution of both scaling parameters (TCSA and LA) spatially sampled over orchard, application of the scaling relationships have been done using the average value for the plot instead of the individual values of the trees, greatly simplifying the up-scaling operation.

The same Gaussian-type distribution was verified on the other plots so that scaling from Tsf on plot A to the other plots was similarly done, considering that plots A, B and $\mathrm{D}$ had the same planting density, using the respective average TCSA or LAI.

For eddy covariance measurements, a first consideration about the quality check of data comes from the footprint analysis carried out, over a one-week period (from 15th to 21st of August, 2006), following the methodology proposed by Schuepp et al. (1990) (data not shown). This week was chosen in the middle of experimental period in order to better check consistency of EC results.

This analysis ensured the respect of the fetch requirements, confirming that the measurements were done entirely within a well-developed olive orchard boundary layer and, thus correctly expressed the local fluxes (Barcza et al., 2009). As a further confirmation, the energy balance closure (obtained by plotting turbulent fluxes against net radiation summed to the soil heat flux) evidenced a high degree of closure (Fig. 4).

Comparison of the relationships between the daily integrals of EC-estimated evapotranspiration (ETec) and up-scaled (TCSA-adjusted) sap flow ET estimates (ETsf) is reported in Figure 5, separately for each prevailing wind direction. For each wind direction, ETsf was linearly related to ETec, with a closer relationship for the SE flux provenance, reflecting the fact that the latter relationship comes from direct up-scaling of sap flow data to plot A. The common regression line was highly significant, even if a higher variability was observed at high ET values.

A comparison of hourly (Fig. 6) and daily (Fig. 7) variation of ETec and ETsf, carried out considering the prevailing wind direction in a 30-minute period, is presented during 20 days chosen within a period scarcely affected by the presence of liquid water (rain, dew formation or irrigation water) evaporating from canopy or soil surface. Under these conditions it can be assumed that ETec should be only affected by tree transpiration and soil evaporation and, in this sense, it should be directly comparable to ETsf. During this period, a good agreement was found, both on an hourly and a daily basis. Only in $10 \%$ of the cases ETec overestimated ETsf, in a small extent (days 238 and 249). Similarly to what observed for scaling from tree level to plot A, the choice of scaling parameter (TCSA or LAI) did not affect the results as can be observed in Figure 7.

We conclude that:

- Eddy covariance measurement of orchard evapotranspiration can be considered a reliable reference for up-scaled sap flow estimations of ET;

- Sap flow data can be used as a replacement (proxy) of eddy covariance when atmospheric conditions invalidate the application of this technique to assess ET;

- Up-scaling sap flow measurements in a non-uniform orchard can be done taking into account simple structural differences among plots. Even in presence of old trees, it was in fact possible to satisfactorily up-scale SF data using LAI. The Gaussian distribution of all orchard structural scaling parameters we have recorded in this study very frequently holds in low- or medium-density orchards, where tree to tree competition is low;

- Up-scaling sap flow data could be possible sampling only a limited number of trees for sap flow measurement and a large sample of trees for the scaling parameters.

\section{ACKNOWLEDGMENTS}

Authors wish to thank the "Azienda Agricola Tenuta Rocchetta di Angela Consiglio", for their hospitality. Authors are also grateful to Dr. A. Cappello and A. Sammartano of the Sicilian Extension Service (UOB-Castelvetrano) for their enthusiastic 
cooperation.

\section{Literature Cited}

Barcza, Z., Kern, A., Haspzpra, L. and Kljun, L. 2009. Spatial representativeness of tall tower eddy covariance measurements using remote sensing and footprint analysis. Agric. Forest Meteorol. 149: 795-807.

Dragoni, D., Lakso, A.N. and Piccioni, R.M. 2005. Measuring Transpiration in Apple Trees using Heat Pulse Sap Flow Gauges Calibrated with Whole-Canopy Gas Exchange. Agric. Forest Meteorol. 130: 85-94.

Fernandez, J.E., Palomo, M.J., Diaz-Espejo, A., Clothier, B.E., Green, S.R., Giron, I.F. and Moreno, F. 2001. Heat-pulse measurements of sap flow in olives for an automating irrigation: tests, root flow and diagnostics of water stress. Agric. Water Manage. 51: 99-123.

Giorio, P. and Giorio, G. 2003. Sap flow of several olive trees estimated with the heat pulse technique by continuous monitoring of a single gauge. Environmental and Experimental Botany 49: $9-20$.

Green, S., Clothier, B. and Jardine, B. 2003. Theory and Practical Application of Heat Pulse to Measure Sap Flow. Agron. 95: 1371-1379.

Hutley, L.B., O'Grady, A.P. and Eamus, D. 2001. Monsoonal influences on evapotranspiration of savanna vegetation of northern Australia. Oecol. 126: 434-443.

Kondo, J. and Saisuga, N. 1990. A parameterization of Evaporation from bare soil surface. American Meteorological Society: $385-389$.

Schaeffer, S.M., Williams, D.G. and Goodrich, D.C. 2000. Transpiration in cottonwood/willow forest patches estimated from sap flux. Agric. Forest Meteorol. 105: 257-270.

Schuepp, P.H., Leclerc, M.Y., Macpherson, J.I. and Desyardins, R.L. 1990. Footprint prediction of scalar fluxes from analytical solutions of the diffusion equation. Bound. Layer Meteorol. 50: 355-373.

Williams, D.G., Cable, W., Hultin, K., Hoedjes, J.C.B., Yepez, E.A., Simonneaux, V., Erraki, S., Boulet, G., De Bruin, H.A.R., Chehbouni, A., Hartogensis, O.K. and Timouk, F. 2004. Evapotranspiration components determined by stable isotope, sap flow and eddy covariance techniques. Agric. Forest Meteorol. 125: 241-258.

\section{Tables}

Table 1. Orchard features and tree phytometric parameters.

\begin{tabular}{lccccccc}
\hline Plot & $\begin{array}{c}\text { Age } \\
\text { (years) }\end{array}$ & $\begin{array}{c}\text { Tree } \\
\text { spacing } \\
(\mathrm{m})\end{array}$ & $\begin{array}{c}\text { Area of } \\
\text { the plot } \\
(\mathrm{ha})\end{array}$ & $\begin{array}{c}\text { Trunk cross } \\
\text { sectional area } \\
(\mathrm{TCSA})\left(\mathrm{cm}^{2}\right)\end{array}$ & $\begin{array}{c}\text { Canopy land area } \\
\text { projected on the } \\
\text { ground }\left(\mathrm{m}^{2}\right)\end{array}$ & $\begin{array}{c}\text { Tree height } \\
(\mathrm{m})\end{array}$ & $\begin{array}{c}\text { Leaf area } \\
\text { index } \\
(\mathrm{LAI})\end{array}$ \\
\hline $\mathrm{A}$ & 12 & $5 \times 8$ & 2.57 & $321 \pm 8$ & $13.56 \pm 1.2$ & $3.7 \pm 0.2$ & $3.4 \pm 0.1$ \\
$\mathrm{~B}$ & 16 & $5 \times 8$ & 2.48 & $463 \pm 41$ & $22.97 \pm 0.7$ & $3.5 \pm 0.1$ & $3.0 \pm 0.1$ \\
$\mathrm{C}$ & 150 & $7 \times 7$ & 3.69 & $873 \pm 83$ & $20.71 \pm 4.5$ & $3.4 \pm 0.2$ & $3.0 \pm 0.1$ \\
$\mathrm{D}$ & 12 & $5 \times 8$ & 2.15 & $225 \pm 19$ & $13.25 \pm 1.5$ & $3.7 \pm 0.2$ & $2.6 \pm 0.1$ \\
\hline
\end{tabular}




\section{Figures}

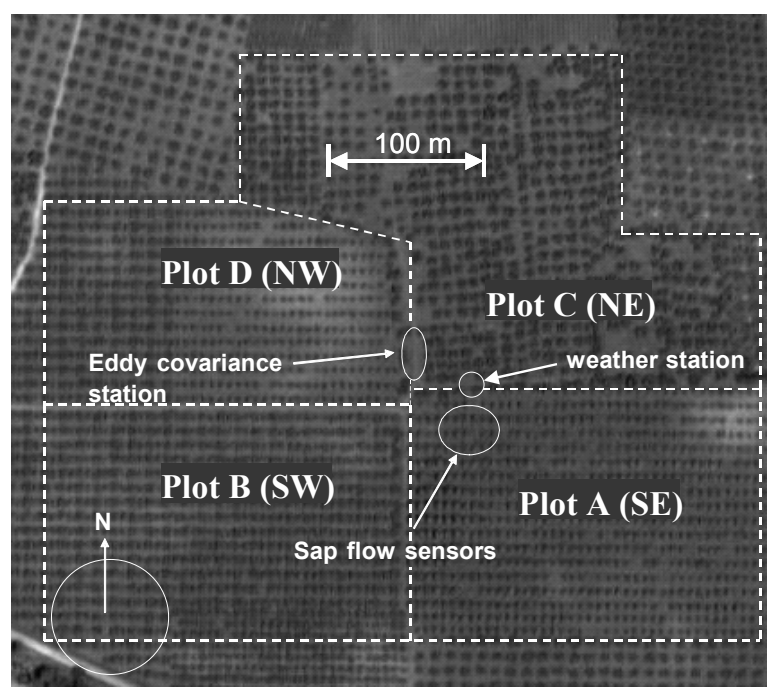

Fig. 1. Map of the olive orchard with indication of the different plots and layout of the sensors.
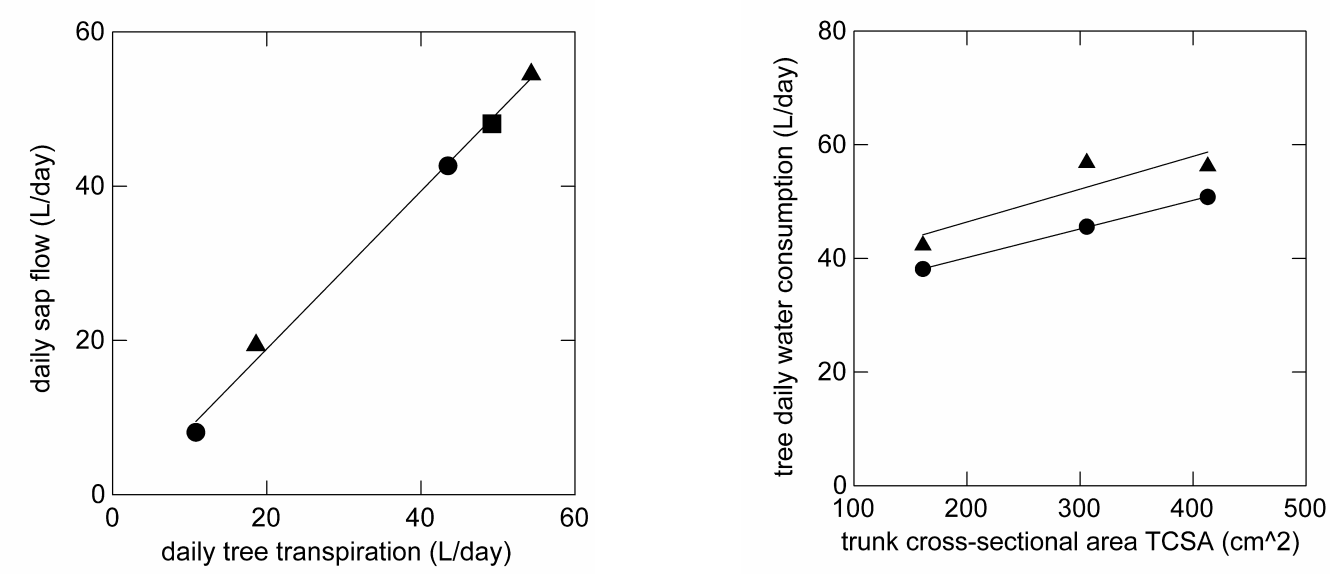

Fig. 2. Regression between daily transpi- Fig. 3. Relationship between tree daily ration estimated by sap flow sensors after choice of appropriate woundingeffect calibration coefficients $(3.0 \mathrm{~mm}$ for tree $\mathrm{A}$ and $2.6 \mathrm{~mm}$ for trees $\mathrm{B}$ and $\mathrm{C}$ ) and transpiration measured by a whole-tree open-system cuvette. Symbols in figure denote trees A, B and $\mathrm{C}$ (circle, square and triangle, respectively). water consumption values and trunk cross sectional area on day 243 (worst case), and on day 253 (best case). 


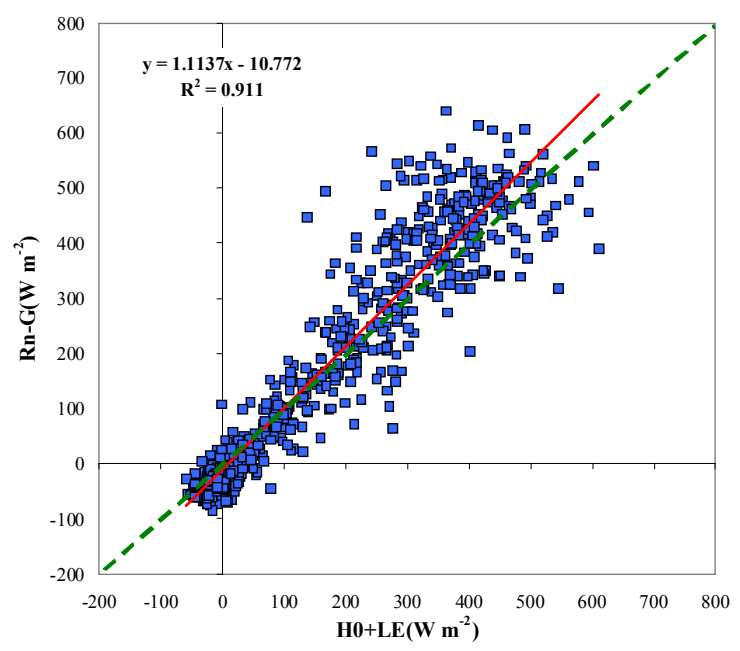

Fig. 4. Eddy covariance energy balance closure from August 1st to August 21st 2006 (Rn: net radiation, G: soil heat flux, LE: latent heat flux, H0: sensible heat flux).

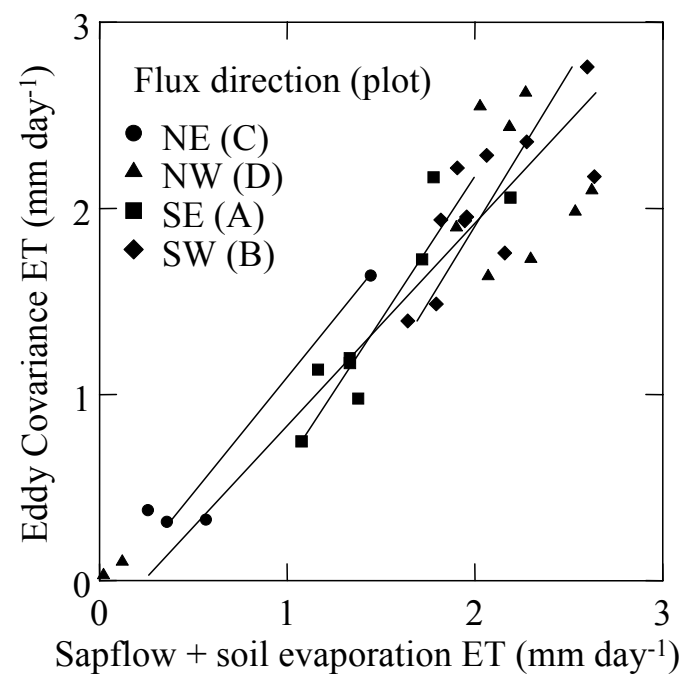

Fig. 5. Daily evapotranspiration (ETec) by eddy covariance vs. up-scaled sap flow (ETsf). Within plot regressions were calculated according to the prevailing wind direction ( $>6$ hours during daytime). Common regression line (all wind directions): $\mathrm{EC}=$ $0.002+0.957 * \mathrm{SF} ; \mathrm{R}^{2}=0.854$. 


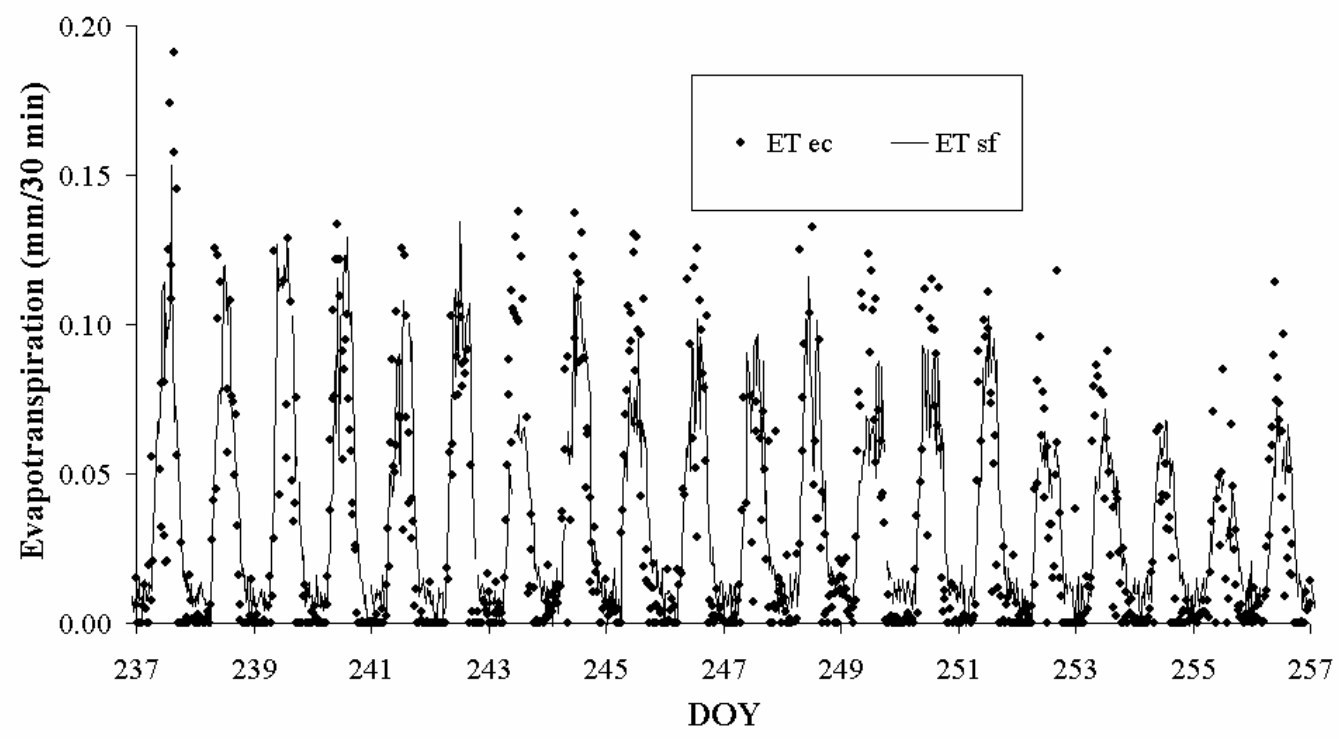

Fig. 6. Comparison between evapotranspiration measured by eddy covariance (ETec) and up-scaled sap flow (ETsf) from DOY 237 to 257.

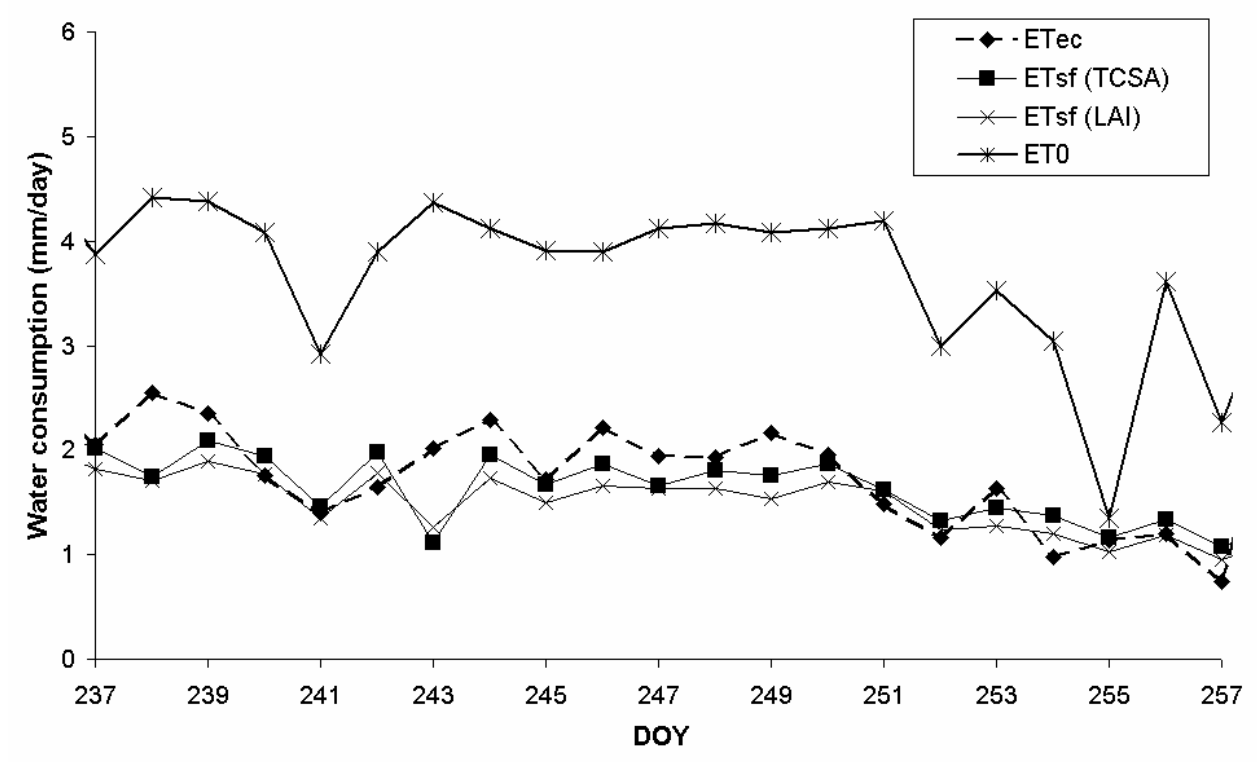

Fig. 7. Trends of reference evapotranspiration (ET0) and daily evapotranspiration measured by eddy covariance (ETec) and up-scaled sap flow (ETsf) estimated by two different scaling parameters (TCSA and LAI). 